\title{
¿LOS NUEVOS SEMINARISTAS?
}

Autor: Lorenzo Trujillo. Rector del Seminario Mayor de Ciudad Real.
Más que una tipología ofrece su impresión, nos invita a ciertas preguntas y a contemplar los rasgos que percibimos en los seminaristas de hoy. Nos alerta de posibles peligros $y$ nos descubre elementos positivos. Bajo un adecuado discernimiento, acogida y formación.

DOI: https://doi.org/10.52039/seminarios.v49i167.845

Querido amigo:

Me pides que exponga, para los lectores de "Seminarios", algo acerca de los "nuevos seminaristas", los jóvenes que se preparan para el sacerdocio. No entra en mis posibilidades hacer un estudio sobre los tipos de joven que acuden hoy a los seminarios, sus diferencias con generaciones anteriores, así como sus dotes y carencias. Trato habitualmente un número exiguo de seminaristas; si capto determinados rasgos, ¿no será fruto de la coincidencia de varios individuos no representativos? Además, soy parte interesada y, en cierta manera, instancia judicial por oficio. Lo único que puedo ofrecer es una impresión razonada, una meditación en clima familiar.

Hablamos de los "nuevos seminaristas": esta expresión me la ha sugerido una novela que hoy pocos recordarán -"Los nuevos curas", de Michael de Saint Pierre-. El recuerdo de aquel contraste tan artificial como exagerado (cura angelical frente a curas marxistas), me 
empuja a hacerme a mí mismo una llamada a la cordura. Las caricaturas fáciles y generalizadoras pueden ser muy pedagógicas, pero hay que estar atentos a que no se tomen al pie de la letra. Mi opinión -te la adelanto ya-es que la tipología sigue siendo variadísima y difícil de encasillar, si bien creo percibir que aumenta una cierta tendencia clerical. No puedo asegurarlo y, además, caso de ser cierto, ignoro si es un fenómeno coyuntural, si se puede y hasta dónde se puede generalizar, si es coherente con los rasgos del joven "actual", etc. Me voy a ocupar exclusivamente de esta "variante", no porque la considere general, o dominante; es por si acaso coincidiera con tendencias extraeclesiásticas y, en ese caso, resultara más probable su crecimiento y necesidad de orientación.

Me reúno frecuentemente con sacerdotes con ocasión de retiros, cursillos, asambleas, etc. Oigo que comentan con cierto malestar: "Está llegando a los seminarios una generación de jóvenes que, antes de cualquier ordenación, gustan exhibirse en hábito talar (elegante y caro), que nada quieren saber del sufrimiento de los hombres sus hermanos, que vivirian de buena gana entre nubes de incienso, que conversan de "trapitos" de sacristía y de ascensos eclesiásticos, que no quieren oír hablar de equipo, de pastoral de conjunto, etc." Acusaciones más o menos precisas, más o menos exageradas e injustas, de infantilismo, clericalismo, conservadurismo preconciliar, etc. Esta crítica se basa en el contraste con la generación de los setenta, de cuyos miembros suele partir. Como he adelantado, creo que la percepción tiene "fundamento in re", pero hay que discernir, interpretar y, sobre todo, no valorar negativamente sin reflexión previa.

Por eso y para empezar, tenga la dimensión y la importancia que tenga esta "cuña" que parece aparecer en el horizonte, quisiera dar un toque de atención a quienes se manifiestan con agresividad y menosprecio. Haría, a modo de ejercicio ascético, una serie de preguntas o, si se quiere, de interpelaciones en forma de preguntas:

1. ¿Por qué no acuden, en mayor número, candidatos más "fronterizos", más seculares, más "encarnados"? ¿Quizá porque esos se quedan en voluntarios como aquel cura "que iba para santo y se quedó en canónigo"? 
2. ¿Por qué no brotan "espontáneamente" vocaciones a la entrega ministerial desde ciertas pastorales? ¿No será que en la entraña de esas pastorales está enquistada una concepción muy insuficiente del sacerdocio de Cristo, de la naturaleza mistérica de la Iglesia, de la necesidad constitucional del ministerio ordenado? Habría que examinar con toda sinceridad si tanta insistencia en el compromiso, en los valores, no oculta, de hecho, la Fuente de donde mana y corre todo compromiso y todo valor.

3. ¿Por qué una generación de curas extraordinariamente generosa ha resultado tan estéril en cuando a la sucesión ministerial? Ninguna ha estado más cerca de los jóvenes, más próxima en actitudes, comprensión, amistad.

4. ¿Tiene derecho quien no ha generado un discipulado capaz de escuchar la llamada, a criticar a los que son llamados por otros canales?

5. ¿Se puede considerar un buen ejercicio sacerdotal el que apenas se preocupa de la sucesión? ¿No se habrá transmitido subliminalmente menosprecio por el sacerdocio mismo a pesar de haberse dejado la piel en el ejercicio de algunas de sus tareas?

6. ¿No constituirán esos seminaristas una llamada del Espíritu Santo ante cierta posible inconsistencia de la generación que ahora vive su ocaso? Si muchos de nosotros, por la forma de vida, nos hemos convertido en meros "agentes de pastoral" laicizados, abdicando de un sacerdocio que obliga a vivir de cara a Dios en medio de los hombres, ¿no vendrán ellos a llenar un vacío real, aunque sea con riesgo de exageración y desequilibrio? Recuerdo una tira del humorista Quino, el autor de Mafalda, en que un anciano muy estirado observa ciertas

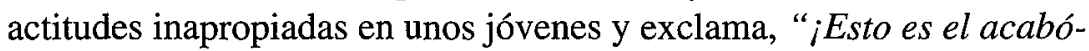
se!"; no sé si la misma Mafalda u otro personaje, completa la frase: “...del comenzóse en ustedes". Hay cosas que parecen contrarias y son, meramente, sucesivas.

Hablamos demasiado y necesitamos callar y contemplar para comprender. He querido empezar por donde deseo terminar; este apartado podría ser la conclusión, debería serlo. Prefiero, no obstante, adelantarlo para que esté presente en todo el discurso. 
¿Reedición corregida y aumentada del viejo clericalismo? Aquí se debería hacer un análisis sobre el momento de la Iglesia, sobre los tumbos pendulares del postconcilio. Los excesos secularistas anteriores anunciaban una respuesta más o menos en esta onda. Algo de lo que se podría decir va implícito en las preguntas que antes he formulado.

Bajo el término "clericalismo" (como bajo su opuesto, "anticlericalismo") hay muchos estratos semánticos que no siempre se distinguen. El DRAE recoge tres acepciones: "Nombre que suele darse a la influencia excesiva del clero en los asuntos políticos", "Intervención excesiva del clero en la vida de la Iglesia, que impide el ejercicio de los derechos a los demás miembros del pueblo de Dios", "Marcada afección y sumisión al clero y a sus directrices". El clericalismo es causa y efecto de un paralelismo institucional entre el Estado soberano y nacionalizador, y la Iglesia sociedad completa y autónoma. Una Iglesia que, para no ser asimilada, ha de constituirse en estado independiente, mundo aparte, paralelo, autosuficiente. Exenciones económicas, matrimonio religioso, enseñanza confesional, fuero y estatuto del clero, fueron cuestiones donde se jugaba la identidad y la independencia. Como ocurre siempre, toda solución a un problema tiene efectos secundarios no deseados; el clericalismo es el efecto colateral de esa larga lucha que en occidente ha mantenido la Iglesia en pos de su independencia (programa de la libertas ecclesiae de Gregorio VII).

Además de esos significados que responden a la realidad anterior, creo que tiene una dimensión no incluida en el DRAE, ni en los estudios históricos. Es una dimensión psicológica: modo de ser al margen de lo secular, configuración caracterológica marcada por la separación. Se trata de un cierto angelismo ajeno a la mundanidad, efecto del predominio de la sacristía (sacristanía) como espacio vital y de convivencia enrarecida: eunuquismo por castración de la secularidad. La separación sociopolítica fue generando a lo largo de siglos un estilo de vida clerical que, a su vez, atraía a sujetos que no querían o no podían convivir el estilo secular. Clericalismo político que genera un clericalismo psicológico, y clericalismo psicológico como factor humano que facilita el paralelismo político y cultural: el huevo y la gallina. 
Este "eunuquismo" pudo ser uno de los motivos hondos del rechazo del sacerdocio como tal, por parte de los mismos sacerdotes, durante los años siguientes al concilio. La polémica de los clérigos postconciliares contra su propio clericalismo tiene mucho de reacción histérica de conversos: odio hacia la antigua vida y hacia la institución educativa donde fraguó, antipatía hacia la expresión explícita de la piedad, agresividad contra los ritos, recuperación de la "vida civil" sin matices y con una ingenuidad infantil. Siempre me ha llamado la atención (y molestado) la muletilla que durante años he oído a los seminaristas cuando se prestaban a entrevistas o mesas redondas: "somos normales, jóvenes como los demás jóvenes". Una muletilla que puede indicar algo de complejo, frustración, incomodidad.

Parece que ahora vuelve a reivindicarse la diferencia. Hay motivos justificados, como la necesidad de afirmar la identidad, o de encontrar un modo de vida menos disperso y anónimo, o de asegurar la pertenencia y fidelidad a Jesucristo. Quizá, junto a estos motivos, puede haber otro elemento cultural que, si se enmascara con bellas y nobles palabras, puede perjudicar los anteriores en vez de beneficiarlos. Por eso voy a intentar sacarlo a la luz.

\section{- III -}

Antes de entrar en la descripción de ese motivo, permíteme que recuerde la procedencia genérica de los actuales seminaristas. Aclaro que no es para establecer una tipología ni, menos, una valoración; es para esclarecer los caminos de llegada por si algo tuvieran que ver con ese posible factor cultural correlativo a la tendencia clerical creciente. Habría que distinguir tres procedencias diferentes: los que aun proceden del Seminario Menor, los que vienen de "ámbitos de conversión", $\mathrm{y}$ los que han fracasado en conatos anteriores de socializarse:

1. Los que aun proceden de seminarios menores poseen la impronta del centro donde se han formado. Su mayor o menor apertura al mundo, mayor o menor tendencia clerical, depende, parcialmente, de la orientación de su seminario. El seminarista que se ha formado en el menor suele presentar un perfil personal bastante sano: por un lado, carece de las experiencias traumáticas que hoy son tan comunes en la adolescencia y primera juventud; por otro, el seminario actual no 
rompe su vinculación con su familia ni con su ambiente. En ellos prima la educación frente a la conversión y, lo que les suele sobrar en "sensatez" puede faltarles en frescura religiosa, en fuego y pasión evangelizadores. A veces son demasiado "normales", como ellos insisten machacona e ingenuamente. En principio, se ajustarían con facilidad al modelo "secular" de los años setenta, pero eso puede dar un giro total cuando el seminario menor se ve muy empobrecido en número y solamente perseveran chicos humanamente pobres o empobrecidos por esa angostura; si los "normales" huyen buscando una convivencia más rica y más abierta, por falta de número se puede producir algo análogo a lo que se produjo antaño por clausura educativa. En este caso se puede invertir la figura y ser el seminario menor fuente de rarezas preclericales.

2. Los que vienen de "ámbitos de conversión". Se trata de candidatos que han sufrido una experiencia de conversión posterior a la adolescencia. No sólo en el seno de los llamados "movimientos internacionales"; también en parroquias vivas o en grupos piadosos. Han experimentado la fe que tenían dormida u olvidada. Esa conversión, normalmente, ha ido seguida de un proceso de formación y crecimiento (como un catecumenado) en el seno de comunidades cristianas homogéneas, con una espiritualidad o estilo propio, y con unos ministros sacerdotales que unían a su condición de ministros la de ser vínculos de pertenencia a ese movimiento o grupo. Han experimentado la filiación en la comunidad y han reconocido la paternidad espiritual de sus dirigentes. El converso puede mostrar ciertos excesos religiosos que, sin embargo, no son homologables con la beatería; son fruto de una pasión aun no canalizada del todo que pide que se tome en serio su entrega y que se responda honradamente a su hambre de Dios. Lo mismo que la llegada numerosa de "vocaciones tardías" -procedentes de Acción Católica y engendradas en el compromiso temporal-alteró durante los sesenta la dinámica de aquellos seminarios preconciliares y colaboró a crear un nuevo tipo de cura, la llegada actual de "conversos" alterará sin duda el ambiente de los seminarios y generará un nuevo tipo de cura. ¿Supone eso, necesariamente, un retroceso al clericalismo? No tiene por qué ser así, pero podría suceder. Su posible clericalismo vendría de aislarse del presbiterio por un sentido de pertenencia primario al grupo, o de afirmar la identidad marcando artifi- 
ciosamente la diferencia, o de rechazar a los formadores de los seminarios como sacerdotes sin "pedigrí" espiritual. O sea, regresarían al clericalismo en la medida que fueran reactivos, endogámicos, refractarios a un horizonte abierto. Para decirlo simbólica y metafóricamente: si por recuperar Lumen Gentium olvidaran Gaudium et Spes, si por amor al grupo olvidaran al pueblo, caerían en un clericalismo elitista e ilustrado pero clericalismo al fin y al cabo.

3. Los que han fracasado en anteriores búsquedas de inserción social. Acuden, de cuando en cuando, muchachos que han abandonado sus estudios, que han dado tumbos, que han tenido desajustes en su inserción social. Es más frecuente en personas de cierta edad (en torno a los cuarenta años) que no vienen de aquellos ámbitos de conversión, ni de grupos cristianos especialmente cultivados. No siempre, pero sí en ocasiones, son personas fracasadas, no aptas para abrirse paso ni en lo que se refiere al mundo laboral, ni en lo relativo a la relación con la mujer. El discernimiento en estos casos es difícil por posible ausencia de verdaderos motivos teologales: ¿Qué busca esta persona? ¿Qué ha habido y hay en su fondo que explique tantos años de inercia y de espera? A veces, cuando se admiten, se va descubriendo una falta de valía humana, de entidad (amorfos), que interroga sobre el acierto de dicha admisión. Si la proporción creciera, puede favorecer la aparición del cura que busca ejercer en su lugar de origen, en el seno de su familia, celebrando la misa y poco más; reedición del "cura de misa y olla". Aquí hay fuertes posibilidades de clericalismo por pobreza humana, de clericalismo rutinario al modo del sacristán de León Felipe.

Si buena parte de los seminaristas procedentes del seminario menor no fueran chicos ilusionados y abiertos a la vida; si los neoconversos chocaran con formadores secularistas incapaces de comprender sus efluvios piadosos y se bloquearan en el momento de la conversión; si bastantes de la hora undécima fueran "mozos viejos" aburridos, sin oficio ni beneficio, el resultado puede ser, ciertamente, un cambio en la actitud general en el sentido anteriormente indicado: deterioro de la humanitas y blindaje defensivo mediante la superestructura de un mundo artificial, ritualista, paralelo, el clericalismo angelical. Mucho más si existiera un factor cultural, común a los jóvenes actuales, que tendiera a camuflarse en un estilo clerical y que casara muy bien con su falsedad. ¿Existe? Me arriesgo a decir tonterías por falta de compe- 
tencia en la materia, pero dado el carácter interrogativo de este escrito, intentaré expresar algo de lo que intuyo.

\section{- IV -}

Quedándonos en ese tipo que pudiera estar aumentando, atisbo que en su gestación subyace otro factor extraeclesial, cultural. Se trata de la evolución de la virilidad en este momento de despertar compulsivo de la mujer y de intento de borrar las diferencias de género. No me refiero directamente al problema de la genitalidad, o sea, de la homosexualidad, un asunto que habría que afrontar con valor y con seriedad teórica y práctica. Ni siquiera utilizo la palabra "virilidad" con un sentido prioritariamente sexual; quiero expresar la posición relacional y social del varón en la actualidad. Sobre la homosexualidad, lo único que me permito apuntar, una vez más, es la tremenda irresponsabilidad de ciertos obispos y superiores a la hora de admitir a personas que han sido rechazadas por otros seminarios. En el artículo me refiero únicamente a candidatos que no presentan tendencias homosexuales ni tampoco desequilibrios emocionales graves, pero cuyas características pueden tener relación con una retracción social del varón.

Ignoro si los estudios de índole sociológico o psicológico pueden aportar algo en este sentido. Desde mi estrecho mirador, sí me parece constatar un aumento de varones más indefinidos en la virilidad, al menos respecto a un patrón de virilidad anterior a esta revolución afectiva que se inició en los sesenta. Se observa, por ejemplo, un aumento de estos rasgos: (1) menos afición a los deportes competitivos, (2) mayor búsqueda de entornos afectuosos, (3) aumento del sentido hogareño frente a la vida en éxodo, (4) gusto estético superficial (artesanías decorativas), (5) pérdida de la capacidad de abstracción en favor del pensamiento débil, (6) sumisión a los estados de ánimo al modo de la histeria, (7) tolerancia pasiva más que caridad activa, (8) falta de interés por la mujer como enigma y misterio, etc. Abundan más (creo) las maneras suaves, ambiguas. Es como si estuviesen impregnados de una dosis de feminidad fuerte. Y repito que no me refiero a los homosexuales, sino a muchachos que no son conscientes de tener tendencias de este tipo, ni son calificados de tales, ni dan indicios en estudios de personalidad. Son jóvenes instalados en una adolescencia que dura demasiado y de la que no saben o no pueden salir para convertirse en adultos. 
¿Es esto generalizable? Ciertamente entre los seminaristas que conozco, no. ¿Responde a una nueva configuración y experiencia de la virilidad fuera del ámbito eclesial? Es posible, pero no puedo asegurarlo. De hecho, parece que, frente a la mayor agresividad de la mujer, el varón se retira acobardado de la plaza pública, de la calle, y busca el refugio del hogar cálido. A veces explota en violencia destructora (violencia doméstica o callejera), a veces se repliega a sucedáneos místicos. Es como una incapacidad para entenderse como varón, como si no supiese serlo. Al caer como características propias las que siempre se entendieron como tales, ¿en qué consiste ser varón? El padre (al menos en nuestro entorno) cada vez pinta menos en lo que atañe a la educación; la influencia de la madre y de sus estados de ánimo va en aumento (parece); encuentro, cada vez con más frecuencia, familias donde las exigencias educativas proceden directamente de la madre mientras el padre se hace cargo de la comprensión y la ternura; es como si los padres varones hubieran envejecido de pronto y se hubiesen convertido en abuelos. (Las posibilidades de observación que ofrece el seminario menor, apuntan por aquí de modo aparentemente creciente; puede que mi experiencia no sea extrapolable, pero encaja con otros datos) La misma propaganda permanente de la homosexualidad creo que genera más inseguridad en los varones que en las mujeres acerca de su comportamiento de género.

\section{$-\mathrm{V}$ -}

Si fuera cierto que este varón -fruto y proyección de una mujer que rechaza la diferencia profunda de género en aras de la igualdad a conseguir- se hace más común y frecuente en toda la sociedad, no sería de extrañar que aumentara su proporción en los seminarios, más aun si estos ofrecen un ministerio con las características clericales ya apuntadas. La mezcla de ambas cosas podría desembocar en esas tendencias clericales que denuncian los sacerdotes maduros:

1. Tendencia a refugiarse en el espacio sagrado y a abandonar la calle. El espacio sagrado es el hogar cristiano, el lugar de la Presencia y de la nueva vida. Este espacio se concreta, sobre todo, en el templo parroquial con su pila bautismal y Eucaristía dominical. No es un espacio cerrado sobre sí, sino lugar de envío y de éxodo hacia la vida 
pública, hacia la "calle" (misión). Cerrarse en ese espacio trae consigo desinterés por el hombre, por la cultura "profana", por los problemas sociales y políticos. Lo mismo que antes pudo darse una mezcolanza so pretexto del necesario compromiso, ahora puede darse una huída con la coartada de la necesaria recuperación de identidad cristiana: ¿siguen siendo los gozos y angustias de los hombres, gozos y angustias de la Iglesia representada por estos jóvenes? Esa forma de ser consistiría, en el fondo, en un infantilismo, una incapacidad para salir del hogar familiar y pisar el espacio público, la calle. Podríamos llamarla "efeboclericalismo".

2. Tendencia a un ritualismo concebido como valor en sí mismo. La liturgia es fuente y culminación de la vida cristiana; está sujeta a la disciplina eclesial y vive de una objetividad que no puede ser apropiada por el celebrante. No hay vida cristiana sin participación en el espacio sacramental, especialmente eucarístico y penitencial. Esto se ha olvidado y se ha dejado deteriorar. De muchos modos: desde caer en la estupidez de un "cristianismo" ( $₫$ ?) sin confesión de fe y sin sacramentos, hasta convertir la celebración de la Eucaristía en la puesta en escena del estado de ánimo del grupo y de la "creatividad" del presidente. Pero si repugna el descuido y el subjetivismo litúrgico, ¿puede satisfacer el ritualismo de la tilde y del círculo perfecto en el manejo del incensario?

3. Tendencia al autoritarismo, especialmente ofensivo para las mujeres. Al ocupar el espacio intraeclesial de modo muy estático y al tener un fuerte sentimiento de la dignidad, el choque con la mujer, que ocupa ahora el mismo espacio con anhelos de responsabilidad no del todo equilibrados, puede estar servido. La violencia verbal, tan propia de los "débiles" (mujeres, mariquitas, adolescentes), encuentra en estos sujetos la posibilidad de "callar" a las mujeres. Frente al varón respetuoso, que descuida aspectos internos y deja en manos de los fieles muchas decisiones, ahora es todo lo contrario; hasta el dominio de los "trapitos" es reivindicado por este varón eclesiástico.

Pero junto a estas tendencias, o, incluso, en el fondo de las mismas, puede descubrirse alguna más positiva y prometedora:

4. Tendencia a buscar las raíces cristianas antes que las consecuencias. Ese volver al hogar sacramental también puede significar una búsqueda de lo esencial, casi perdido, con la posibilidad de poste- 
riores despliegues y desarrollos. Los seminaristas de antaño, de algún modo, fuimos "hijos de la calle", hijos del ambiente más que del mismo seminario. La salida y estancia en parroquias "comprometidas", así como en movimientos de ambiente, tenía un influjo muy fuerte en la formación; a veces, un influjo contrario al del seminario. En la formación intelectual jugaba más, en ocasiones, la búsqueda personal (artículos de revistas punteras, cursillos someros) que la ratio institucional. Se daba por supuesto lo esencial, para centrarse en las consecuencias de índole social, política, etc. El que ahora se viva un cierto retorno al "hogar" no está mal, siempre que no encubra una incapacidad para la vida pública.

5. Tendencia a anteponer la contemplación de Jesús sobre la acción pastoral. Quizá esa tendencia a la intimidad, a las relaciones personales, quizá esa veta de ternura, sitúe a estos candidatos más próximos a Betania que a Cafarnaúm. El "cristiano" originario de Galilea puede oír con tal intensidad el programa de las bienaventuranzas que llegue a olvidar Quién las ha encarnado, en Quién consisten: por la "causa" de Jesús se puede olvidar a Jesús mismo. Los Doce, al parecer, no entendieron la acción de aquella mujer que dilapidaba una fortuna para ungir al Señor. Marta se dispersó en mil actividades (muy nobles y meritorias) y corrió el riesgo de perder lo único necesario que María había descubierto y defendía contra la presión del entorno "eclesial". Quizá estos muchachos estén más cerca del Discípulo Amado que del Pedro galileo: la cuestión es si la intimidad con el Señor los conduce a una misión pública, o a una amistad narcisista; si el amor personal a Jesús los empuja a entregar la vida por las ovejas del Amigo, o a fabricar un cómodo refugio que les evite pasar las noches al raso contando estrellas y buscando ovejas perdidas.

Estas tendencias ni se dan en todos, ni quizá en la mayor parte, ni en la misma medida, ni con la misma "mezcla". A la hora de una actuación concreta es preciso dejar las generalizaciones y contemplar la persona concreta en su originalidad.

\section{- VI -}

Si lo hasta aquí razonado no es del todo incorrecto, creo que el asunto se debe concretar en tres puntos: (1) discernimiento, (2) actitud receptiva, y (3) educación adecuada. 
1. El necesario discernimiento. En el apartado anterior acabamos de ver qué diversos pueden ser los aspectos, las dimensiones, las tendencias, que laten en esta posible tipología ( que, caso de existir realmente, puede no ser mayoritaria!) Lo primero que se impone es el discernimiento persona a persona. Lo que en un sujeto puede ser motivo suficiente para negar la aptitud, en otro, cuando se contempla en la integridad personal, puede tener distinto significado. Por ejemplo: no es igual un beato inteligente (y abierto a la Verdad por inteligente), que otro estúpido y cerrado en su terquedad obsesiva o fanática; no puede tratarse del mismo modo a un entusiasta de la celebración litúrgica, a la vez humano y servicial, que a otro cuya vida se separa claramente de lo que con tanto esmero celebra. De todas formas, conviene discernir las mismas tendencias antes de llegar al discernimiento personal y definitivo. En tres pasos: a) Hay que distinguir entre virilidad no desarrolla$d a$ (fragilidad infantil, efebismo adolescente) y tendencias homosexuales propiamente dichas. Cierto que existe una relación posible e, incluso, puede haberla concreta: la inmadurez es una indeterminación que deja abierto un camino hacia la posible homosexualidad; la homosexualidad siempre lleva consigo una inmadurez de base. Pero la continuidad no tiene por qué darse necesariamente; cierto infantilismo puede encubrir una inocencia limpia, procedente de la gracia y potencialmente muy creativa: el adolescente José, rechazado por sus hermanos, es potencialmente un varón fecundo y sabio; lo llegará a ser con la ayuda de Dios y con su conducta honesta, pero necesitará mucho tiempo y mucho sufrimiento; me pregunto si José hubiese llegado a ser el sabio de Israel caso de haber continuado como hijo-nieto del anciano Jacob, presumiendo de lindas túnicas ante sus rudos hermanos. En este discernimiento, es obligado excluir a los candidatos que presenten tendencias homosexuales; tendencias reales, no sólo conductas. Lo cierto es que la presión cultural y la falsa misericordia (tolerancia), la necesidad de sacerdotes y la "seguridad" de estos candidatos (nunca abandonan, perseveran), conducen en más de una ocasión a hacer la vista gorda y dejar pasar. b) Dentro de lo que es inmadurez y nada más (efebismo), conviene seguir investigando: $¿$ Se trata de inmadurez biológica (eunuquismo, mariquita) o de problemas de índole socio-psicológica (falta de modelo masculino, dominio materno, "sororismo")? ¿Qué profundidad tiene, qué arraigo en la personalidad (aquí juega la edad), cómo afec- 
ta al conjunto de la misma? ¿Es consciente el sujeto de esa limitación y la integra en su camino de esperanza, o la rechaza y encubre bajo una falsa madurez? ¿Ama su virilidad hasta agradecerla, pedirla, luchar por ella? El problema en estas deficiencias de conducta social es lo que Daniel Goleman llama "el punto ciego", o sea, el no querer conocer y afrontar lo que todos, desde fuera, ven y sufren. Cuando se da este terror a verse tal cual, es muy difícil un progreso sano. $\mathrm{Y}$, en ese sentido, una dirección espiritual que dé por bueno todo lo que aparece como piadoso, puede cerrar el camino a la maduración. c) Un tercer paso en el discernimiento: si ese infantilismo no homosexual se traduce en las tendencias que hemos dibujado en el anterior apartado $\mathrm{V}$, es preciso discernir un elemento espiritual de primera importancia, la humilde obediencia a la Palabra del Señor, la sencillez de la persona abierta al discernimiento del seminario concreto y al camino educativo alli ofrecido, sin huidas a falsos padres que permiten esquivar las exigencias de maduración. O sea, la aceptación de la vocación como oblación y muerte de la ilusión o proyección subjetiva. El tipo infantiloide, si además está imbuido de soberbia espiritual, es muy peligroso y utilizará todos los medios para escapar de una formación seria. Estos iluminados sí que son personas frágiles que buscan seguridad, superioridad, incienso y dominio sobre los fieles. Pero no son todos; es preciso distinguir.

2. Lo he apuntado antes: son los padres quienes tienen que cambiar cuando nace un hijo para dejar espacio a su novedad. Engendrar es dar gratuitamente la propia sustancia, la propia vida. No se trata de perpetuar la especie, ni de producir clónicos. Por eso, si fuera verdad (en la medida que lo sea) que un nuevo tipo de jóvenes es llamado por el Señor, los presbiterios que los han de acoger (no sólo los formadores) tendrán que replantear su propia mentalidad y forma de vida. Si se quiere salvar lo mejor de la espiritualidad sacerdotal de los años postconciliares, es imprescindible purificarla de tópicos y de corruptelas. A mi juicio el "cura laico" no es el prototipo del Concilio sino un subproducto accidental; está llamado a extinguirse para que nazca el verdadero presbítero; y sólo la oblación de este "cura-hombre" evitará un neoclericalismo regresivo y efébico, porque entonces será padre y dejará lo mejor de sí en quienes vengan.

Me viene un recuerdo que puede resultar algo chocante e impropio pero que, precisamente por eso, puede golpear ciertas conciencias 
bloqueadas. Hace unas décadas, todavía era frecuente en algunos países o regiones el que aquellos patriarcas machistas se avergonzaran de sus hijos adolescentes cuando estos tardaban en mostrar rasgos externos de virilidad; se daba el caso de forzarlos violentamente a la iniciación con prostitutas expertas. Esos "machos" se equivocaban: la causa del alejamiento de sus hijos respecto a la virilidad eran ellos mismos, sus padres. El hijo, seguramente, com-padecía el rencor de su madre hacia el marido opresivo, violento, infiel, brutal... y, no queriendo ser ese varón, el hijo se deslizaba por resentimiento hacia el rechazo absoluto de la virilidad.

Si esos seminaristas se dan y en la medida que se den, ¿no constituirán una llamada a los presbíteros actuales para que abramos un espacio religioso más hondo en nuestra secularidad mortecina? $¿$ Vamos a rechazar a los pocos que hoy se ofrecen como sucesores porque no nos vemos reflejados y realizados en ellos? ;Ojo con el resentimiento generacional! Muchos sacerdotes y obispos que vivieron con intensidad el cambio del Vaticano II pueden hoy sentirse defraudados y humillados al ver el "triunfo" de quienes ellos despreciaron como reliquias del pasado. Hasta pueden sentirse postergados injustamente. Por eso me resulta admirable la postura de amor a la Iglesia, de servicio humilde, en personas que, aparentemente, han sido relegadas en el escalafón eclesiástico. Esto sí que es cristiano; y no es nuevo. ¿Acaso no sucedió lo mismo con la generación preconciliar que se perdió en el olvido para dar paso a una oleada de jóvenes (no siempre humildes ni fieles) que escalaron las responsabilidades y jubilaron anticipadamente a muchos hombres probados? La vida es así y no hay que escandalizarse demasiado. No imitamos a Saturno, devorando a los hijos para crecer y sobrevivir; somos hijos en el Hijo que, mediante el sacrificio de la vida, hacen posible que el Padre sea reconocido, santificado, glorificado, en nuevos, inesperados y originales hijos.

3. El tercer punto sería la formación adecuada para este tipo, pero, por su importancia merece un nuevo apartado autónomo.

\section{- VII -}

Supuesta la existencia de un número significativo de seminaristas con las características que hemos descrito, y supuesto también el discernimiento y la acogida adecuados, la formación se convierte en el 
camino para purificar motivaciones, equilibrar rasgos y completar una visión del mundo y de la Iglesia. Para ir directamente al asunto, voy a enumerar una serie de pautas educativas que me parecen esenciales:

1. Formación desde las raíces de la gracia. No se "sana" a un beato de su superficialidad religiosa escandalizando adrede su conciencia con ironías, desprecio de lo sagrado, etc. Por el contrario: la clave para educar a uno con tendencias clericales está en el cultivo de la piedad auténtica que desenmascara positivamente la hipocresía religiosa. Cualquier camino educativo cristiano tiene que fundarse en acción primera de Dios, en la obediencia a la Palabra, en la oración, en la práctica sacramental asidua y cuidada. Incluso cuando conviene algún tipo de examen o terapia psicológica, es fundamental que se haga desde el amor a la Verdad y desde la confianza en el Señor; sólo desde esta base es posible mirar sin miedo nuestros defectos y vacíos, evitar el bloqueo, la autojustificación, la desesperanza; quien no confía en la gracia no podrá aguantar la caída de la máscara personal, el tiempo de espera en la obscuridad; generará nuevos subterfugios con la ayuda inconsciente del psicólogo. La sicología no es la última medida de la persona; se puede entrar en el Reino con alguna que otra neurosis bien llevada, pero ciertamente no es posible con una aséptica y egoísta normalidad.

2. Nueva comprensión unitaria de la virilidad. Creo que no nos percatamos de la importancia que este asunto tiene hoy. Los poderes culturales están presionando para borrar o diluir la diferencia de género. Separar la sexualidad de la procreación, justificar el aborto, naturalizar la homosexualidad como un género de vida más, abrir las mentes a la clonación, ¿no responde todo al mismo proyecto? $\mathrm{El}$ mito del andrógino es hoy un proyecto avalado por la "ciencia", exigido por la "libertad", estimulado por la "economía". Es la base del neognosticismo. Sostener la univocidad de la familia, vincular sexualidad y procreación, diferenciar los géneros, defender el derecho a la vida de los no nacidos y el derecho a ser gestado en el vientre la propia madre, es hoy el acto político más importante en defensa de la humanidad. Llamar a varones al ministerio sacerdotal es una acción que desborda lo intraeclesial y lo ministerial.

Pero esto exige comprender la diferencia de género desde unos conocimientos nuevos, con nueva hondura. ¿En qué consiste ser 
varón? ¿En qué consiste ser mujer? ¿Cómo se puede educar en algo que no se comprende? Se hacen simposios y congresos sobre cualquier tema, pero este asunto es soslayado en la Iglesia o tratado con gran superficialidad. No conozco un verdadero diálogo católico para comprender el asunto desde una óptica interdisciplinar. Es muy urgente.

3. Educación del cuerpo del candidato. El infantilismo adolescente tiene unos rasgos corporales que pueden ser, en parte, reeducados. No es el fondo, pero ayuda. Me refiero, sobre todo, a movimientos, timbre de la voz y descontroles emocionales. a) Me da la impresión (solo puedo hablar de impresiones) de que llegan al seminario menor, cada vez en mayor número, adolescentes con un cierto "ramalazo". Repito que no se trata de homosexuales, ni puede decirse que tengan esa tendencia. Sobre todo, se delata en el movimiento de las extremidades, brazos y piernas. No entro en detalle, pero creo que el deporte competitivo y en equipo, especialmente el fútbol, ayuda bastante a controlar estos movimientos y a reeducarlos... si solo se trata de eso. b) En segundo lugar, la voz. La voz atiplada no es signo de menor virilidad; ni mucho menos. En un hombre público suena mal. Es frecuente en eclesiásticos; una vida célibe empuja a la delicadeza, a los modales "diplomáticos"; si a esa pureza de costumbres, y al posible infantilismo anterior que ahora estamos tratando, añadimos la posible afectación de quienes repiten siempre las mismas ceremonias sin un contacto profundo con el ser de las mismas, la cosa puede ser muy llamativa. Pues bien, al menos esa afectación puede corregirse; la naturalidad en el decir, la reflexión mientras se habla, la moderación del volumen, serenarán esa voz y la hará menos llamativa. c) Por último, las explosiones histéricas (excesos verbales, descontroles nerviosos sin motivo, importancia excesiva de los estados de ánimo) también revelan inmadurez y han de ser corregidos. En conjunto y resumen, se trata de educar en la mesura, la naturalidad, la contención. "Yo no soy mi estado de ánimo" tendría que ser el lema educativo para los jóvenes actuales. El cura no puede ser una "sibila" alucinada y descomedi$\mathrm{da}$, sino un humilde sacramento personal de la Brisa suave y de la Palabra gestada en el silencio.

4. Participación en el trabajo manual productivo y humilde. Hay trabajos agrícolas temporeros o tareas similares donde el seminarista, además de lograr unos ingresos que le hacen más independiente de su 
familia y de innecesarios benefactores, palpa la suerte de los humildes, adquiere fuerza corporal y seguridad en sí mismo, conoce los sentimientos del pueblo en momentos de desinhibición campechana, etc. El trabajo físico asalariado es un antídoto estupendo y un tratamiento eficacísimo contra el efebismo y la soberbia clerical precoz. También resulta una ascesis seria y actual para educar los sentidos y orientarlos a la Verdad. Me resultan escandalosas algunas exigencias que ciertos sacerdotes jóvenes (a veces privilegiados por altos estudios) plantean: respecto a casas parroquiales, vestiduras u objetos de culto, comida y comodidades en instituciones de formación, etc. La pobreza del discípulo de Jesús es parte esencial de la imitatio, y la costumbre de trabajar manualmente otorga humildad y hombría.

5. Desinstalación de lo celebrativo como fin en sí. La celebración litúrgica es centro del espacio sacramental donde el Resucitado se hace presente a su Iglesia y la "contagia" el Espíritu con que el Padre ha glorificado su Humanidad para siempre. El menosprecio de este espacio so pretexto de la encarnación, o su apropiación mediante un protagonismo "creativo" en gestos o fórmulas, constituye una inversión demoníaca del sacerdocio ministerial. La mesura y la moderación son imprescindibles en todo... salvo en la caridad. La sacramentalidad tiene su culminación en la liturgia pero no se reduce a las ceremonias: nace del Acontecimiento real (pascua) y se dirige a las vidas reales (cotidianas) de los participantes. Aunque en una hipótesis imposible la Iglesia se olvidara un día de celebrar la Navidad, esta sería imborrable de la historia de los hombres e influiría en ella. Actualmente es impagable la aportación que los liturgistas están haciendo a la teología sacramental (¿quién no disfruta y agradece los estudios de Giraudo o de Aldazábal por citar a alguno?), pero si no se tiene cuidado se puede dejar en un segundo término lo que aconteció y acontece, la historia real que en el signo y en la oración es realizada aquí y ahora. Si así sucediera, abriríamos el camino para un clericalismo nuevo y más pernicioso. Ese varón a medio cocer, encontraría en la liturgia (mal entendida), en la fiesta popular, el proscenio ideal para su narcisismo infantil, para su falsa realización social; de ahí a la recuperación de fastos impropios del evangelio, sólo hay un paso.

6. Apertura de la inteligencia al ser. El clericalismo, como "forma" personal, es propio de varones más frágiles e indiferenciados. 
Todos hemos observado lo aficionados que son estos últimos a la decoración en general, a la teatralidad, a las apariencias y revestimientos. No suponen estas palabras un menosprecio de artes nobles como el teatro o la decoración, ni de quienes se dedican a ellos, pero sí, en estos casos, una sospecha de que ese infantilismo se traduce en una cierta superficialidad, en un amaneramiento versallesco, en un amor al adorno y al disfraz, en una confusión del aparecer con el ser. La percepción del ser, la apertura de la inteligencia a los niveles hondos de la realidad, es, sin duda, terapéutica y maduradora. Ese candidato frágil y blando padece casi siempre un rechazo hacia el pensamiento "fuerte", hacia las preguntas duras; vive de dulces intuiciones religiosas y se alimenta de ceremonias. Es fideísta por naturaleza, o mejor, por deficiencia de naturaleza. El estudio serio y continuado, la ascética de la inteligencia, el esfuerzo de la abstracción, sacan su mirada de los decorados de la vida para buscar el fondo de la misma; pero les puede resultar duro y odioso. El amaneramiento es fruto, también, del mimetismo y de la ausencia de preguntas radicales.

7. Formar en la imitación del Buen Pastor. Cuando hay conciencia de lo que supone ser sacerdote (sacramento del Sacerdocio único del Señor), cuando no hay apropiación, se orienta la formación hacia la caridad pastoral: al servicio del sacerdocio bautismal de personas muy concretas que han de ofrecer sus vidas en medio de la lucha por la vida. No son los fieles para el sacerdote, sino el sacerdote ministerial para los fieles bautizados en el Sacerdocio de Cristo. El contacto con las personas, con sus alegrías y angustias, con sus problemas reales; la proximidad a los humildes, a los enfermos, a los marginados; todo esto, cuando es fruto del amor al Señor que envía ("Pedro, ¿me amas...? Apacienta mis ovejas"), realiza, santifica, normaliza. Es la clave para una nueva etapa como lo fue para las anteriores; no sólo para una tipología sino para todas.

Amigo Alonso, termino como empecé: advirtiendo que este no es el retrato del seminarista de hoy sino la aproximación a una posible tendencia; recordando que hasta el Señor acogió a los que el Padre le dio sin poner condiciones; gritando que es urgente comprender para discernir; soñando que se abrirán nuevos caminos de formación, más adecuados e integrales. Son inquietudes y tanteos. Interroguemos a Dios y pidamos su Espíritu para seguir buscando sin desfallecer. 